Fetal Diagnosis and Therapy
Fetal Diagn Ther 2020;47:188-197

DOI: $10.1159 / 000501430$
Received: January 4, 2019

Accepted after revision: June 7, 2019 Published online: August 15, 2019

\title{
Barriers to Sonographer Screening for Fetal Heart Defects: A U.S. National Survey
}

\author{
Nelangi M. Pinto ${ }^{a}$ Kevin A. Henry ${ }^{b}$ Guo Weic Xiaoming Sheng ${ }^{c}$ Tom Green ${ }^{c}$ \\ Michael D. Puchalski ${ }^{a} \quad$ Janice L.B. Byrne ${ }^{d}$ Anita Y. Kinney ${ }^{\mathrm{e}}$ \\ ${ }^{a}$ Department of Pediatrics, Division of Cardiology, University of Utah, Salt Lake City, UT, USA; ${ }^{b}$ Department of \\ Geography, Temple University, Philadelphia, PA, USA; ' Department of Pediatrics, Division of Biostatistics, University of \\ Utah, Salt Lake City, UT, USA; ${ }^{d}$ Department of Internal Medicine, Department of Obstetrics and Gynecology, University

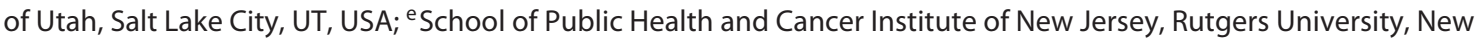 \\ Brunswick, NJ, USA
}

\section{Keywords \\ Congenital heart defect · Screening · Prenatal diagnosis . \\ Ultrasound $\cdot$ Cross-sectional survey}

\begin{abstract}
Objective: We surveyed obstetric sonographers, who are at the forefront of the screening process to determine how barriers to prenatal cardiac screening impacted screening abilities. Methods: We performed a cross-sectional national survey of obstetric sonographers in the United States using a sampling frame from American Registry of Diagnostic Medical Sonography mailing lists. The web survey measured the ability to obtain and interpret fetal heart images. Several cognitive, sociodemographic, and system-level factors were measured, including intention to perform cardiac imaging. Regression and mediation analyses determined factors associated with intention to perform and ability to obtain and interpret cardiac images. Subgroup analyses of sonographers in tertiary versus nontertiary centers were also performed. Results: Survey response rate either due to noncontact or nonresponse was $40 \%$. Of 480 eligible sonographers, $\sim 30 \%$ practiced in tertiary settings. Sonographers had lower
\end{abstract}

intention to perform outflow views compared to 4 chambers. Higher self-efficacy and professional expectations predicted higher odds of intention to perform outflow views (OR 2.8, 95\% Cl 1.9-4.2 and 1.9, 95\% Cl 1.1-3.0, respectively). Overall accuracy of image interpretation was $65 \%( \pm 14 \%)$. For the overall cohort and nontertiary subgroup, higher intention to perform outflows was associated with increased accuracy in overall image interpretation. For the tertiary subgroup, self-efficacy and feedback were strongly associated with accuracy. Conclusions: We identified several modifiable (some heretofore unrecognized) targets to improve prenatal cardiac screening. Priorities identified by sonographers that are associated with screening success should guide future interventions.

C 2019 S. Karger AG, Basel

\section{Introduction}

Congenital heart disease (CHD) is the most common birth defect and a leading cause of neonatal deaths; yet, screening for CHD is challenging [1]. Approximately $80 \%$ of CHD occurs in fetuses of mothers with-

\section{KARGER}

(c) 2019 S. Karger AG, Basel

E-Mail karger@karger.com

www.karger.com/fdt
Nelangi Pinto, MD, MS

Division of Cardiology, University of Utah

81 N. Mario Capecchi Drive

Salt Lake City, UT 84113 (USA)

E-Mail Nelangi.pinto@ hsc.utah.edu 
out risk factors [2, 3]. Currently, prenatal cardiac screening occurs as part of a second trimester fetal anomaly scan [4]. While research and experience indicate that high-quality cardiac screening should detect $>80 \%$ of CHD, only $30-50 \%$ of CHD is detected in the United States and most developed countries, with high variation between centers, regions, and countries [5$10]$.

Strategies to improve detection have been studied for the past 3 decades. Those previously found to have some success include: targeted sonographer training [11-13], screening views [14-16], tiered screening strategies [17, 18 ], and employing novel technologies such as 3-D or real-time 3-D sonographic imaging [19, 20]. These strategies have not been widely implemented, especially in the United States, where highly varied training and practice environments limit feasibility.

Effective interventions for improving CHD detection need to be practical, feasible, and relevant for sonographers who perform in low-risk settings, where the majority of prenatal screening for heart defects occurs. In the United States, obstetric sonographers who obtain screening images of the fetal heart and the physicians who interpret these scans are on the frontline of the screening process. Sonographers often may not communicate with the interpreting physician [21]. For this reason, they must recognize whether their imaging adequately captures the important structures of the fetal heart and in some cases differentiate between "normal" and "abnormal" images to demonstrate their findings for the interpreting physician. If they are unable to recognize and obtain standardized images that highlight the key cardiac findings, CHD detection may be missed [22, 23]. The input of sonographers who perform imaging in a variety of clinical settings is central to understanding which strategies might be most effective and sustainable for improving CHD detection in practice.

We conducted a national survey of obstetric sonographers using a web-based instrument previously piloted regionally [23]. The aim of this study was to (1) investigate cognitive, sociodemographic, and system-level barriers and facilitators with screening for sonographers across the United States and (2) prioritize intervention targets and understand the association of these factors with sonographer ability to interpret cardiac screening images. Furthermore, we sought to explore differences in identified barriers and their associations with sonographer ability by type of practice setting (tertiary/high-risk pregnancy imaging centers vs. community hospitals/clinics).

\section{Materials and Methods}

\section{Study Design}

We performed a cross-sectional nationally representative survey of obstetric sonographers in the United States. The target population was sonographers who perform second trimester obstetric screening (or fetal anomaly) ultrasound scans. Participants were recruited from a comprehensive list of sonographers registered with the American Registry of Diagnostic Medical Sonography (ARDMS) who designated obstetric ultrasound as their field. Sonographers who had performed a second trimester obstetric ultrasound independently in a nontraining capacity in the prior 6 months were eligible (determined by the first 2 questions in the survey). To ensure participation from sonographers in rural settings, we employed a stratified probability sampling strategy; we created a sample of 2,000 from a national list of ARDMS mailing addresses geocoded using Esri ${ }^{\odot}$ street network files and ArcGIS software ${ }^{\complement}$. Geocoded cases were assigned a rural versus urban designation based on census tract using Rural Urban Commuting Area Codes $[24,25]$. Sampling was stratified on (1) U.S. Census region (proportionate sampling based on registration) and (2) rural - urban designation (disproportionate oversampling for a 1:1 distribution). We used a multiphase mixed-mode, evidence-based recruitment strategy including a prenotification letter, E-Mail follow-up with a survey link, and 3 additional electronic reminders [26, 27].

We adapted a survey that was previously developed for a prior regional pilot study [23] utilizing input from sonographer focus group discussions. The first section of the survey measured factors influencing sonographers' intention to perform and ability to perform cardiac screening images. Candidate factors were based on published behavioral theory frameworks previously used to understand evidence implementation, health professional behaviors, and adoption of new technologies [28-34]. These, along with salient themes identified by focus groups in our previous work, were used to develop an explanatory model of potential factors that contribute to sonographer performance of prenatal cardiac screening [23]. The main factors measured for this study included self-efficacy, outcome expectancy, perceived ease of use, feedback, professional expectancies, and knowledge. Most measures were adapted from the literature $[33,35]$. Previously validated scales had excellent internal consistency (Cronbach alpha range 0.80-0.94) as well as high internal convergent and discriminant validity and predictive validity. Self-efficacy measured a sonographer's confidence or belief about their own ability to interpret screening images and was measured with a 6 -item scale that asked about their confidence in obtaining images in different circumstances. Outcome expectancy (usefulness) measured sonographer's beliefs about the usefulness of obstetric cardiac screening views (2-item scale). Perceived ease of use (ease of use) measured the degree to which sonographers felt obtaining screening images was free of effort (4-item). Feedback was measured using a novel 4 -item scale validated in our regional survey that specifically asked sonographers to rate how both how important they felt feedback on their cardiac imaging was and how much feedback on their cardiac scanning they received. Professional expectations measured sonographer belief about whether screening was expected by peers, superiors, or professional guidelines (3-item). Knowledge was measured using 5 questions around screening techniques and the current status of prenatal detection. Behavioral intention to perform cardiac screening was measured with several scale items (intent to perform any cardiac screening, 
4 chamber screening, and outflow tract screening) both for its direct influence on performance as well as a mediator of other important factors that influence screening. All items, with the exception of knowledge, were measured using a 5-point Likert response scale.

Since measuring actual sonographer scanning ability on a national scale was unrealistic for this study, we used a surrogate measures. These included self-reported time to obtain cardiac imaging, self-reported ability to obtain 4 chamber and outflow tract screening views, and accuracy in image interpretation. The second part of the web survey presented 20 video clips of fetal heart screening views. Sonographers were asked to interpret 4 sets of 5 images each. The first set asked sonographers to interpret whether 4 chamber view images provided were adequate or inadequate for screening purposes since sonographers are responsible for obtaining adequate images to present providers for interpretation. The 2 nd set of images asked them to interpret whether the 4 chamber view images provided were normal or abnormal. The remaining 2 sets repeated the same for outflow tract view images. Images that mimicked barriers such as maternal body habitus, suboptimal fetal lie, and early and late gestational ages were also incorporated. Two fetal cardiologists and a sonographer specializing in fetal echocardiography independently reviewed candidate images and only those with $100 \%$ inter-rater reliability were included. To decrease the impact of the image choice itself on sonographer performance, we had 3 sets of 20 images that were randomly selected for each survey participant.

\section{Analysis}

The main outcome was accuracy of image interpretation. Descriptive summaries of the primary demographics and survey items were performed. Sonographers were designated as practicing in a tertiary setting if they performed any obstetric scanning at a high-risk obstetrics clinic or an imaging center associated with such a clinic. Scales for each measured factor were tabulated for raw and mean scores with SDs. Measured factors were examined for possible collinearity using pairwise correlations and variance inflation factors. Those with correlations higher than 0.7 were reevaluated when fitting the models described below and the item with the most explanatory relevance was retained. The main analyses evaluated the association of the independent variables (selfefficacy, outcome expectancy, perceived ease of use, feedback, professional expectancies, and knowledge) with (1) behavioral intention to perform outflow tract imaging using a logistic regression model and (2) overall percent accuracy using a linear regression model. Univariate regression of factors with self-reported time to obtain cardiac images and ability to obtain views were also performed. Models for intention included covariate adjustment for facilitating conditions (a measure of the availability of equipment and/or resources that supported cardiac scanning) and experience/training and models for accuracy included these as well as image test number (since there were 3 sets of images). Models for accuracy adjusted for all covariates when analyzing relationship to behavioral intention, but did not adjust for intention when evaluating all other covariates since intention may have mediated their association with accuracy of interpretation in our model.

Linear regression models were repeated separately for the specific secondary outcomes of accuracy of interpretation of 4 chamber view images and outflow images. Additionally, exploratory analyses examining factors associated with accurate interpretation of inadequate/adequate and normal/abnormal images were performed. Finally, a subgroup analysis of sonographers practicing in tertiary versus nontertiary practice settings was performed for regression models.

In addition to regression modeling, a mediation analysis [36, 37] was performed which considered behavioral intention to examine outflow tracts as an intermediate variable in the causal pathway for the overall accuracy of image interpretation as an additional sensitivity analysis.

The study was approved by the University of Utah Institutional Review Board.

\section{Results}

Of 2,000 sonographers with addresses registered through the ARDMS where contact was attempted by mail, the response rate among nonreturns was $40 \%$ ( $n=$ 758); 278 were ineligible based on lack of recent performance of obstetric ultrasounds. Participant $(n=480)$ demographics are presented in Table 1 . Most sonographers were female with an average of $17( \pm 10)$ years of experience. About $1 / 3$ performed ultrasounds in a high-risk or tertiary care setting. Sonographers that performed scans in nontertiary settings compared to those in tertiary settings did not differ significantly in age or experience, but did differ with regard to number of scans performed per week (12 vs. 15 scans, respectively). In tertiary settings, sonographers reported longer times on average to obtain cardiac screening images. Cardiac imaging was not a required part of the second trimester fetal anomaly scan for $12 \%$ of sonographers in their practices.

The majority of sonographers (78\%) indicated that interpreting physicians never performed any scanning themselves, with another $12 \%$ stating physicians sometimes scanned but for less than half of their studies. The proportion of sonographers who had verbal interaction with the interpreting physician was higher - $20 \%$ every time, $38 \%$ did for less than half their scans, but $20 \%$ reported never speaking with a physician.

\section{Independent Factors}

The raw averages for the main factors that could influence cardiac imaging are summarized in Table 1. In general, sonographers reported that professional expectations for cardiac screening were generally high, but raw scores for adequacy of feedback or facilitating conditions for performing cardiac screening were lower. In general scores for outflow imaging in terms of both self-efficacy and outcome expectancy/usefulness were lower than for 4 chamber imaging. The average score for the knowledge 
Table 1. Characteristics and summary of primary survey predictors and outcomes for entire cohort and by practice setting

\begin{tabular}{|c|c|c|c|c|c|c|c|}
\hline \multirow{2}{*}{$\begin{array}{l}\text { Factor } \\
\text { Gender, female }\end{array}$} & \multicolumn{2}{|c|}{ Entire cohort } & \multicolumn{2}{|c|}{ Nontertiary } & \multicolumn{2}{|c|}{ Tertiary } & \multirow{2}{*}{$\frac{p \text { value* }}{0.16}$} \\
\hline & 318 & $291(91.5)$ & 215 & $200(93.0)$ & 103 & $91(88.3)$ & \\
\hline Experience, years & 474 & $17.49 \pm 9.90$ & 336 & $17.34 \pm 10.18$ & 138 & $17.83 \pm 9.20$ & 0.62 \\
\hline Age, years & 317 & $45.66 \pm 11.56$ & 215 & $45.44 \pm 11.76$ & 102 & $46.12 \pm 11.15$ & 0.63 \\
\hline Ultrasounds per week & 471 & $15.39 \pm 14.48$ & 333 & $12.23 \pm 12.47$ & 138 & $23.03 \pm 16.10$ & $<0.001$ \\
\hline Scan at tertiary center & 480 & $138(28.7)$ & 342 & & 138 & & \\
\hline \multicolumn{8}{|l|}{ Domain/factor } \\
\hline Professional expectations & 442 & $4.49 \pm 0.86$ & 311 & $4.34 \pm 0.92$ & 131 & $4.85 \pm 0.56$ & $<0.001$ \\
\hline Feedback & 442 & $3.82 \pm 0.91$ & 311 & $3.60 \pm 0.88$ & 131 & $4.35 \pm 0.77$ & $<0.001$ \\
\hline Facilitating conditions & 442 & $3.81 \pm 0.95$ & 311 & $3.58 \pm 0.93$ & 131 & $4.33 \pm 0.79$ & $<0.001$ \\
\hline Self-efficacy $4 \mathrm{C}$ & 446 & $3.70 \pm 0.73$ & 314 & $3.65 \pm 0.70$ & 132 & $3.82 \pm 0.79$ & 0.02 \\
\hline Self-efficacy outflow & 446 & $3.10 \pm 1.00$ & 314 & $2.93 \pm 0.98$ & 132 & $3.50 \pm 0.92$ & $<0.001$ \\
\hline Perceived ease of use outflow & 455 & $3.54 \pm 1.09$ & 321 & $3.30 \pm 1.07$ & 134 & $4.13 \pm 0.91$ & $<0.001$ \\
\hline Knowledge & 339 & $0.70 \pm 0.17$ & 234 & $0.69 \pm 0.17$ & 105 & $0.72 \pm 0.16$ & 0.23 \\
\hline \multicolumn{8}{|l|}{ Outcome } \\
\hline Intention to perform $4 \mathrm{C}$ imaging & 466 & $463(99.4)$ & 331 & $330(99.7)$ & 135 & $134(99.3)$ & 0.51 \\
\hline Intention to perform outflow imaging & 466 & $348(74.7)$ & 331 & $220(66.5)$ & 135 & $128(94.8)$ & $<0.001$ \\
\hline Overall accuracy, $\%$ & 390 & $65.39 \pm 14.24$ & 272 & $63.83 \pm 13.02$ & 118 & $68.99 \pm 16.21$ & $<0.001$ \\
\hline Time to obtain cardiac screening images, min & 466 & $8.99 \pm 6.45$ & 331 & $8.26 \pm 5.42$ & 135 & $10.80 \pm 8.20$ & $<0.001$ \\
\hline Self-reported ability to obtain $4 \mathrm{C}$ & 464 & 459 (98.9) & 330 & $327(99.1)$ & 134 & $132(98.5)$ & 0.63 \\
\hline Self-reported ability to obtain outflows & 464 & $350(75.4)$ & 330 & $227(68.8)$ & 134 & $123(91.8)$ & $<0.001$ \\
\hline Accuracy 4C, \% & 390 & $70.32 \pm 15.30$ & 272 & $68.67 \pm 13.89$ & 118 & $74.12 \pm 17.62$ & 0.001 \\
\hline Accuracy outflow, \% & 369 & $60.51 \pm 16.50$ & 254 & $58.47 \pm 16.65$ & 115 & $65.01 \pm 15.30$ & $<0.001$ \\
\hline Accuracy adequate, \% & 390 & $56.22 \pm 16.42$ & 272 & $55.81 \pm 15.63$ & 118 & $57.16 \pm 18.14$ & 0.46 \\
\hline
\end{tabular}

Figures are numbers, mean \pm SD or $n(\%) . *$ For comparison between nontertiary and tertiary.

module was $70 \%( \pm 17)$. All response averages were higher from sonographers who performed in tertiary settings with the exception of knowledge scores that did not differ significantly. The largest differences between types of setting were for feedback, facilitating conditions, and selfefficacy and outcome expectancy/usefulness for outflow tract view imaging.

\section{Behavioral Intention}

Most sonographers answered that they intended to perform cardiac screening "most" or "every time" and responses were similar when asked about intention to perform imaging 4 chamber views (Table 1 ). Responses were more variable for behavioral intention regarding outflow tract screening and $>12 \%$ of sonographers "never" or "almost never" intended to image outflow tracts. In terms of ability, almost all sonographers be- lieved that they could obtain a 4 chamber "most of the time," but only $75 \%$ felt the same about outflow tract views.

\section{Image Interpretation}

Image interpretation was completed by 390 of the 480 sonographers who started the survey. The overall accuracy in image interpretation was $65 \pm 14 \%$ with lower accuracy for interpreting outflow tract views $(61 \pm 17 \%)$ and for determining the adequacy of cardiac images for screening purposes $(56 \pm 16 \%$; Table 1$)$.

\section{Regression Models}

Primary models included only 339 respondents who had completed all assessments for accuracy as well as knowledge. When self-efficacy and outcome expectancy/ usefulness measures for both 4 chamber and outflow 
Table 2. Factors associated with cardiac imaging behaviors and abilities using a generalized linear regression model

\begin{tabular}{|c|c|c|c|c|c|c|}
\hline \multirow[t]{2}{*}{ Parameter } & \multicolumn{2}{|c|}{$\begin{array}{l}\text { Time to obtain images } \\
\text { (minutes to complete image) }\end{array}$} & \multicolumn{2}{|c|}{$\begin{array}{l}\text { Self-reported } \\
\text { ability }-4 \mathrm{C}\end{array}$} & \multicolumn{2}{|c|}{$\begin{array}{l}\text { Self-reported } \\
\text { ability - outflow }\end{array}$} \\
\hline & estimate & $p$ value & estimate & $p$ value & estimate & $p$ value \\
\hline Facilitating conditions & 0.558 & 0.310 & -0.435 & 0.658 & 0.830 & 0.002 \\
\hline Professional expectations & -0.076 & 0.898 & -0.267 & 0.813 & 0.462 & 0.071 \\
\hline Feedback & 1.420 & 0.011 & 0.461 & 0.683 & 0.107 & 0.694 \\
\hline Outcome expectancy & 0.269 & 0.668 & 0.049 & 0.97 & -0.107 & 0.710 \\
\hline Self-efficacy & -2.073 & $<0.001$ & 2.925 & 0.118 & 1.561 & $<0.001$ \\
\hline Year of experience & -0.002 & 0.947 & 0.08 & 0.396 & 0.002 & 0.923 \\
\hline
\end{tabular}

Bold values are significant $(p<0.05)$.

views were included in the model, they created effects in opposite directions likely due to measured and unmeasured collinearity (Table 2). As a result, we chose to include only self-efficacy and outcome expectancy/usefulness for outflow tracts (which had wider distributions than those for 4 chambers) in the models.

For the univariate linear regression analysis, increased self-efficacy (or confidence in abilities) was associated with decreased self-reported time to obtain cardiac images. There were no measures associated with self-reported ability to obtain 4 chamber images, but facilitating conditions and self-efficacy were associated with improved self-reported ability to obtain outflow tract views.

In examining behavioral intention to perform outflow images, each additional increase of 1 on the Likert response scale for self-efficacy in ability to obtain outflow views resulted in a 2.8 (95\% CI 1.9-4.2) higher odds of the intent to always perform outflow views after controlling for other predictor variables (Table 3). A similar increase in professional expectations for cardiac screening increased odds 1.9 (95\% CI 1.1-3.0) times. Knowledge, feedback, facilitating conditions, and experience were not associated with intention. In the nontertiary subgroup, higher professional expectations and self-efficacy were similarly associated with intention, but higher outcome expectancy/belief in the usefulness for outflow imaging was also associated with higher intention to image outflow tracts (OR 1.6, 95\% CI 1.0-2.7).

Overall accuracy in image interpretation was associated with increasing behavioral intention to image the outflow tracts in the overall cohort ( $~ 5 \%$ increase for every unit increase in intention; Table 4). Behavioral intention was also positively associated with accuracy in interpreting outflow tract images and if images were normal or abnormal. Self-
Table 3. Multivariable regression of predictors of odds of intention to perform outflow screening images $(n=339)$

\begin{tabular}{lll}
\hline Predictor & \multicolumn{2}{l}{$\begin{array}{l}\text { OR }(95 \% \text { CI }) \text { of intention to } \\
\text { perform outflow imaging }\end{array}$} \\
\cline { 2 - 3 } & overall cohort & $\begin{array}{c}\text { nontertiary } \\
\text { practice }\end{array}$ \\
\hline Professional expectations & $\mathbf{1 . 9 ( 1 . 1 - 3 . 0 )}$ & $\mathbf{1 . 8}(\mathbf{1 . 1}-\mathbf{3 . 0})$ \\
Outcome expectancy outflow & $1.4(0.9-2.3)$ & $\mathbf{1 . 6}(\mathbf{1 . 0}-\mathbf{2 . 7})$ \\
Self-efficacy outflow & $\mathbf{2 . 8 ( 1 . 9 - 4 . 2 )}$ & $\mathbf{2 . 6}(\mathbf{1 . 7}-\mathbf{3 . 9})$ \\
Feedback & $1.5(0.9-2.6)$ & $1.3(0.7-2.3)$ \\
Knowledge & $4.7(0.7-30.0)$ & $3.0(0.4-22.5)$ \\
Facilitating conditions & $1.0(0.6-1.6)$ & $0.8(0.5-1.4)$ \\
Experience & $1.0(1.0-1.0)$ & $1.0(1.0-1.0)$ \\
\hline
\end{tabular}

Bold values are significant $(p<0.05)$.

efficacy in outflow imaging was the only other factor independently associated with accuracy in overall images and all subtypes with the exception of interpreting image adequacy though the estimates of effect were smaller than for behavioral intention (2-3.6\% increase in accuracy across measures for every unit increase in self-efficacy).

Results from the mediation analysis were similar with the exception that knowledge also appeared to have a direct effect on accuracy.

\section{Subgroup Analysis}

For sonographers who practice in tertiary settings, behavioral intention to perform outflow tract imaging was no longer a predictor of accuracy in interpretation (Table $4 \mathrm{~b}$ ), as intention varied little and was high for almost all in this group (Table 2). In the tertiary care subgroup model, self-efficacy for outflow imaging was strongly associ- 
Table 4. Multivariable regression ${ }^{\dagger}$ of predictors of $\%$ change in accuracy of cardiac image interpretation in cohort $(n=339)$

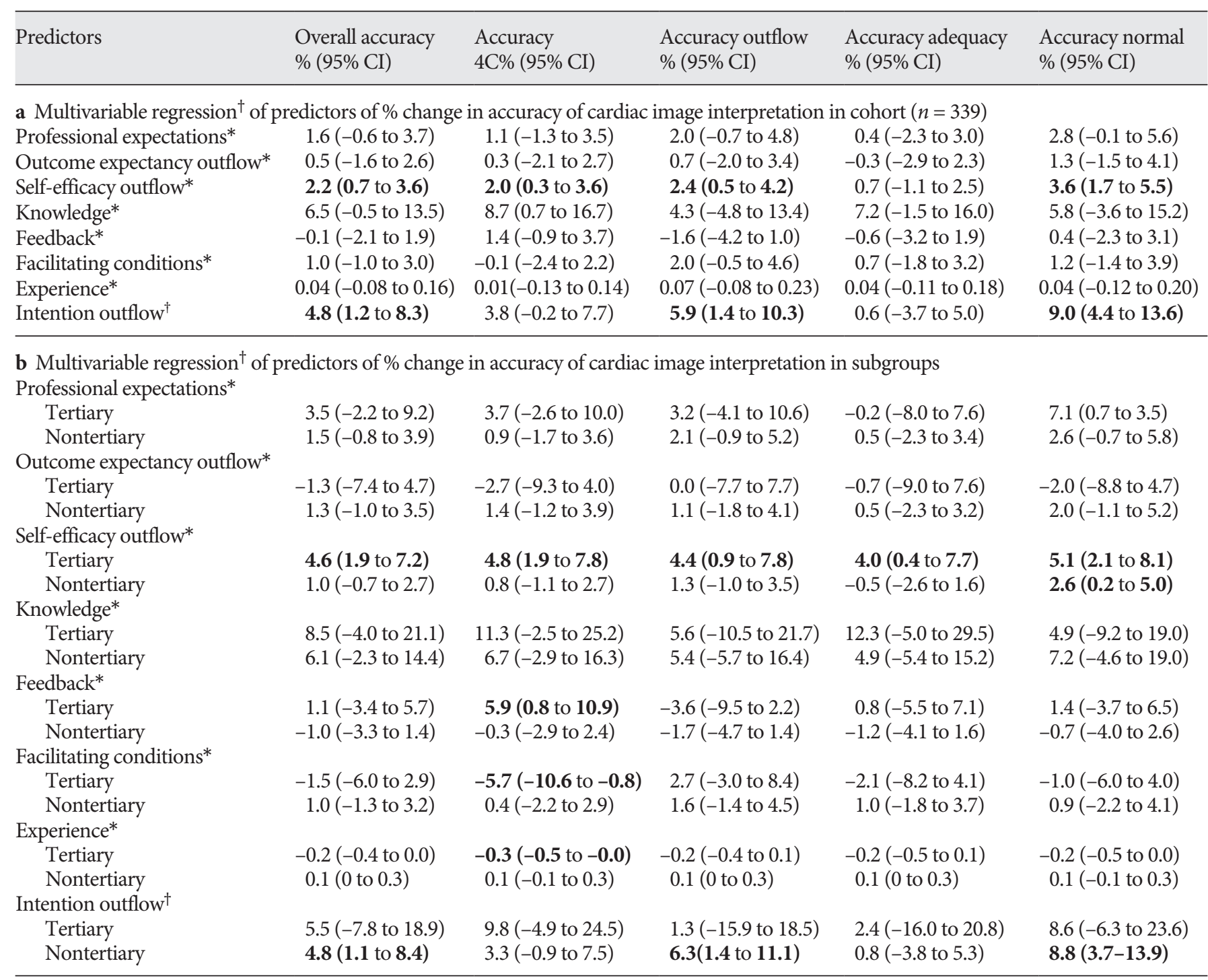

Bold values are significant $(\mathrm{p}<0.05) . *$ Coefficients indicate the estimated mean differences in accuracy \% associated with a one unit increment increase in each predictor variable in a multivariable model jointly including professional expectations, outcome expectancy outflow, self-efficacy outflow, knowledge, feedback, facilitating conditions, and experience as predictor variables, with test number also included as an additional covariate. ${ }^{\dagger}$ Coefficients indicate the estimated mean differences in accuracy \% associated with a one unit increment increase in intention outflow in an expanded multivariable model that includes intention outflow as well as all of the other predictor variables, again controlling also for test number as an additional covariate.

ated with all measures of accuracy (overall and by subtype of image) with no other independent predictors other than feedback for accuracy in interpreting 4 chamber images. For the subgroup of sonographers who practiced only in nontertiary settings, behavioral intention remained strongly associated with overall accuracy as well as accuracy in interpreting outflows and if images were normal or abnormal.

\section{Discussion}

This study extends our previous regional work [23] and is the first national survey of U.S. obstetric sonographers identifying their perceived barriers to prenatal cardiac screening. Several barriers were associated with selfreported imaging ability, intention to perform imaging, as well as their ability to interpret cardiac images. These 
included sonographer's self-efficacy (confidence in performing imaging) and the professional expectations of supervising staff and physicians; for sonographers in nontertiary practice settings, beliefs about the usefulness of cardiac imaging were also important.

As in our regional survey study [23], behavioral intention to perform cardiac imaging views was the strongest predictor of how well sonographers interpreted cardiac images. Modifying behavioral intention requires understanding the motivation behind it $[6,38,39]$. Experience, as measured by years of scanning, was not associated with intention or accuracy of image interpretation and did not correlate with sonographer ratings of self-efficacy or other important predictors. This finding contrasts previous studies [12] and may be related to our measure of specific behavioral factors that may be more important and also, encouragingly, more amenable to modification.

Self-efficacy or confidence in one's ability to scan fetal hearts both directly and indirectly influenced accuracy in interpreting images in our study. Targeted sonographer training, one way to increase self-efficacy, has been undertaken with some local and regional success $[11,13,40$, 41]. In the United States, training and education are highly variable $[4,42]$. National advocacy for more rigorous educational standards and testing of cardiac knowledge and scanning skills may improve self-efficacy. At a local level, maternal - fetal medicine specialists and fetal cardiologists can ensure adequate educational opportunities with hands-on training for their referral regions $[43,44]$.

Professional expectations were also strongly associated with behavioral intention. Strengthening guidelines in 2013 to require inclusion of outflow imaging in second trimester obstetric ultrasounds [45] was an important step in increasing expectations for cardiac imaging. While we launched our survey 6 months after this change, the majority of surveys were completed more than a year after. Yet, there may not have been optimal dissemination. Nonetheless, it is remarkable that a quarter of sonographers did not always perform outflow tract imaging. Canadian guidelines incorporated outflows much earlier and subsequent improvements in detection of cardiac defects suggest that guidelines and professional expectations impact screening [46]. While we did not specifically assess sonographer factors related to other screening views that were not specifically required by national guidelines, there has been increasing focus on the 3 vessel view as an additional more facile screening image for the outflow tracts that may increase detection of abnormal outflow anomalies [16]. This has led the International Society of Ultrasound in Obstetrics and Gynecology guide- lines to recommend (though not mandate) inclusion of this view as part of a comprehensive evaluation of the outflows [47]. Guidelines alone, however, are usually insufficient to change practice and formalizing expectations with audit systems, protocols, or quality improvement initiatives may be necessary [48-51].

Efforts are also needed to improve knowledge around screening imaging methods and to address gaps in understanding the impact of prenatal cardiac screening. Sonographers rated their beliefs in the usefulness of outflow tract views significantly lower than 4 chamber views despite the fact that this view is necessary to capture a significant portion of critical congenital heart defects [52]. This belief or lack thereof in the usefulness of this imaging particularly influenced sonographer's intentions to perform outflow tract imaging in low-risk settings suggesting that sonographers should not only be taught "how" but also "why" these views are necessary.

Our results highlight that efforts to improve prenatal cardiac screening must be tailored to practice setting. While sonographers in community settings did not differ significantly from those in tertiary setting with regard to age, experience, and knowledge, they had lower professional expectations of their imaging, confidence, and perceived usefulness of cardiac screening images. These differences, while not surprising, are concerning since the majority of prenatal screening occurs in low-risk settings $[3,39,53]$.

For sonographers in tertiary centers, efforts need to focus on improving self-efficacy and feedback on imaging [54]. For sonographers in community settings, multifaceted interventions are needed to target the multiple factors that influence their intention to perform fetal heart imaging. While reaching sonographers in low-risk settings is challenging, several recent studies have successfully used decentralized approaches to disseminate education, auditing systems, and screening protocols $[44,48$, 55].

\section{Strengths and Limitations}

Our study may be limited by selection bias; respondents may be more interested in cardiac imaging than nonrespondents. Since we did not mandate responses to all survey items and respondents were anonymous to encourage participation, we were unable to weight our sample. Causal interpretations of our regression models were limited by the cross-sectional observational study design. Though image interpretation is a surrogate measure of true ability to screen for heart defects, performing a similarly scaled study measuring scanning ability and recog- 
nition of abnormalities during scanning would be formidable. While sonographers do not provide official interpretation, interpreting adequacy and relationship to normal of screening images is an essential skill to provide the reading provider with adequate information, especially when images are often presented as still frames [21]. Visual motor and spatial skills including the recognition of expected sonographic anatomy of normal structures is a necessary psychomotor skill for performing high-quality imaging [56]. Finally, our findings were strengthened by basing our design and analysis on previously validated behavioral theory and surveying sonographers across the country.

\section{Conclusion}

This national survey of sonographers identified several modifiable and some heretofore unrecognized intervention targets to improve prenatal screening for heart defects. Interventions must address sonographers' needs and priorities while also addressing system/practice level factors such as minimum standards for education/training and infrastructure to meet the recommended screening metrics to effectively improve prenatal screening for CHD.

\section{Acknowledgments}

This investigation was supported by the University of Utah Study Design and Biostatistics Center, with funding in part from the National Center for Research Resources and the National Cen- ter for Advancing Translational Sciences, National Institutes of Health, through Grant 5UL1TR001067-02 (formerly 8UL1TR000105 and UL1RR025764).

\section{Statement of Ethics}

Subjects in this study have given their written consent. The study protocol has been approved by the University of Utah Institutional Review Board.

\section{Disclosure Statement}

The authors have no conflicts of interest to declare.

\section{Funding Sources}

The research presented herein was supported by a grant from the Saving Tiny Hearts Society.

\section{Author Contributions}

All of the authors have significantly contributed to this endeavor including development of the study design, data collection, statistical analysis, and contribution to the writing of the manuscript. Specifically, Drs. Nelangi M. Pinto, Kevin A. Henry, Xiaoming Sheng, Michael D. Puchalski, Janice L.B. Byrne, and Anita Y. Kinney were all involved in the conception and design of the study. Drs. Nelangi M. Pinto, Guo Wei, Xiaoming Sheng, and Tom Green were involved in the analysis and interpretation of the data. All authors have been involved in drafting and revising the manuscript and have given their final approval for it in its current form.

\section{References}

1 Hoffman JI. Incidence of congenital heart disease: II. Prenatal incidence. Pediatr Cardiol. 1995 Jul-Aug;16(4):155-65.

2 Kleinert S. Routine prenatal screening for congenital heart disease. Lancet. 1996 Sep; 348(9031):836.

3 Stumpflen I, Stumpflen A, Wimmer M, Bernaschek G. Effect of detailed fetal echocardiography as part of routine prenatal ultrasonographic screening on detection of congenital heart disease. Lancet. 1996 Sep;348(9031): 854-7.

4 American Institute of Ultrasound in Medicine. AIUM Practice Guideline for the Performance of Obstetric Ultrasound Examinations. J Ultrasound Med. 2010 Jan;29(1):157-66.

5 Quartermain MD, Pasquali SK, Hill KD, Goldberg DJ, Huhta JC, Jacobs JP, et al. Vari- ation in Prenatal Diagnosis of Congenital Heart Disease in Infants. Pediatrics. 2015 Aug;136(2):e378-85.

6 Khoo NS, Van Essen P, Richardson M, Robertson T. Effectiveness of prenatal diagnosis of congenital heart defects in South Australia: a population analysis 1999-2003. Aust N Z J Obstet Gynaecol. 2008 Dec;48(6):559-63.

7 Stoll C, Garne E, Clementi M; EUROSCAN Study Group. Evaluation of prenatal diagnosis of associated congenital heart diseases by fetal ultrasonographic examination in Europe. Prenat Diagn. 2001 Apr;21(4):243-52.

8 Marek J, Tomek V, Skovránek J, Povysilová V, Samánek M. Prenatal ultrasound screening of congenital heart disease in an unselected national population: a 21-year experience. Heart. 2011 Jan;97(2):124-30.
9 McBrien A, Sands A, Craig B, Dornan J, Casey F. Major congenital heart disease: antenatal detection, patient characteristics and outcomes. J Matern Fetal Neonatal Med. 2009 Feb;22(2):101-5

10 Campaña H, Ermini M, Aiello HA, Krupitzki H, Castilla EE, López-Camelo JS; Latin American Collaborative Study of Congenital Malformations Study Group. Prenatal sonographic detection of birth defects in 18 hospitals from South America. J Ultrasound Med. 2010 Feb;29(2):20312.

11 Carvalho JS, Mavrides E, Shinebourne EA, Campbell S, Thilaganathan B. Improving the effectiveness of routine prenatal screening for major congenital heart defects. Heart. 2002 Oct;88(4):387-91. 
12 Tegnander E, Eik-Nes SH. The examiner's ultrasound experience has a significant impact on the detection rate of congenital heart defects at the second-trimester fetal examination. Ultrasound Obstet Gynecol. 2006 Jul; 28(1):8-14.

13 McBrien A, Sands A, Craig B, Dornan J, Casey F. Impact of a regional training program in fetal echocardiography for sonographers on the antenatal detection of major congenital heart disease. Ultrasound Obstet Gynecol. 2010 Sep;36(3):279-84.

14 Wong SF, Chan FY, Cincotta RB, Lee-Tannock A, Ward C. Factors influencing the prenatal detection of structural congenital heart diseases. Ultrasound Obstet Gynecol. 2003 Jan;21(1):19-25.

15 Tongsong T, Tongprasert F, Srisupundit K, Luewan S. The complete three-vessel view in prenatal detection of congenital heart defects. Prenat Diagn. 2010 Jan;30(1):23-9

16 Yagel S, Arbel R, Anteby EY, Raveh D, Achiron $\mathrm{R}$. The three vessels and trachea view (3VT) in fetal cardiac scanning. Ultrasound Obstet Gynecol. 2002 Oct;20(4):340-5.

17 Sananes N, Guigue V, Kohler M, Bouffet N, Cancellier M, Hornecker F, et al. Nuchal translucency and cystic hygroma colli in screening for fetal major congenital heart defects in a series of 12,910 euploid pregnancies. Ultrasound Obstet Gynecol. 2010 Mar;35(3): 273-9.

18 Bahado-Singh RO, Wapner R, Thom E, Zachary J, Platt L, Mahoney MJ, et al. Elevated first-trimester nuchal translucency increases the risk of congenital heart defects. Am J Obstet Gynecol. 2005 May;192(5):1357-61.

19 Yagel S, Cohen SM, Rosenak D, Messing B, Lipschuetz M, Shen O, et al. Added value of three-/four-dimensional ultrasound in offline analysis and diagnosis of congenital heart disease. Ultrasound Obstet Gynecol. 2011 Apr; 37(4):432-7

20 Bennasar M, Martinez JM, Gomez O, Bartrons J, Olivella A, Puerto B, et al. Accuracy of four-dimensional spatiotemporal image correlation echocardiography in the prenatal diagnosis of congenital heart defects. Ultrasound Obstet Gynecol. 2010 Oct;36(4):45864.

21 Scott TE, Jones J, Rosenberg H, Thomson A, Ghandehari H, Rosta N, et al. Increasing the Detection Rate of Congenital Heart Disease During Routine Obstetric Screening Using Cine Loop Sweeps. J Ultrasound Med. 2013 Jun;32(6):973-9.

22 Chaoui R. The four-chamber view: four reasons why it seems to fail in screening for cardiac abnormalities and suggestions to improve detection rate. Ultrasound Obstet Gynecol. 2003 Jul;22(1):3-10.

23 Pinto N, Sheng X, Keenan HT, Byrne JL, Stanton B, Kinney AY. Sonographer-Identified Barriers and Facilitators to Prenatal Screening for Congenital Heart Disease: A Mixed Methods Study. J Diagn Med Sonogr. 2017;33(1): 3-12.
24 United States Department of Agriculture. Rural-Urban Commuting Area Codes Overview. 2012. Available from: http://www.ers.usda. gov/data-products/rural-urban-commutingarea-codes.aspx.

25 Morrill R. (WWAMI RHRC, Cromartie J (Depatrment of AERS, Hart G (University of ND. No Title [Internet]. RUCA - Rural Health Research Center. 2005. Available from: http:// depts.washington.edu/uwruca/ruca-about. php.

26 VanGeest JB, Johnson TP, Welch VL. Methodologies for improving response rates in surveys of physicians: a systematic review. Eval Health Prof. 2007 Dec;30(4):303-21.

27 Dillman DA, Smyth JD, Christian LM. The Tailored Design Method. Internet, Mail and Mixed-Mode Surveys: The Tailored Design Method. 3rd ed. Hoboken: John Wiley and Sons; 2009. pp. 15-39.

28 Ajzen L. From intentions to actions: A theory of planned behavior. In: Kuhl Beckmann, Jurgen J, editor. Action control: From cognition to behavior. New york: Springer-Verlag; 1985. p. 11-39.

29 Maue SK, Segal R, Kimberlin CL, Lipowski EE. Predicting physician guideline compliance: an assessment of motivators and perceived barriers. Am J Manag Care. 2004 Jun; 10(6):383-91

30 Bandura A. Social Cognitive Theory. In: Vasta R, editor. Annals of Child Development Vol 6 Six theories of child development. Greenwich: JAI Press; 1989. pp. 1-60.

31 Cabana MD, Ebel BE, Cooper-Patrick L, Powe NR, Rubin HR, Rand CS. Barriers pediatricians face when using asthma practice guidelines. Arch Pediatr Adolesc Med. 2000 Jul;154(7):685-93.

32 Cabana MD, Rand C, Slish K, Nan B, Davis MM, Clark N. Pediatrician self-efficacy for counseling parents of asthmatic children to quit smoking. Pediatrics. 2004 Jan;113(1 Pt 1):78-81.

33 Venkatesh V, Morris MG, Davis GB, Davis FD. User acceptance of information technology: toward a unified view. Manage Inf Syst Q. 2003;27(3):425-78.

34 Duyck P, Pynoo B, Devolder P, Voet T, Adang L, Vercruysse J. User acceptance of a picture archiving and communication system. Applying the unified theory of acceptance and use of technology in a radiological setting. Methods Inf Med. 2008;47(2):149-56.

35 Davis FD. Perceived usefulness, perceived ease of use, and user acceptance of information technology. Manage Inf Syst Q. 1989; 13(3):319-40.

36 VanderWeele TJ. Explanation in causal inference: methods for mediation and interaction. Oxford University Press; 2015.

37 VanderWeele TJ, Vansteelandt S. Odds Ratios for Mediation Analysis for a Dichotomous Outcome. Am J Epidemiol. 2010 Dec; 172(12):1339-48.

38 Friedberg MK, Silverman NH, Moon-Grady AJ, Tong E, Nourse J, Sorenson B, et al. Pre- natal detection of congenital heart disease. J Pediatr. 2009 Jul;155(1):26-31, 31.e1.

39 Pinto NM, Keenan HT, Minich LL, Puchalski MD, Heywood M, Botto LD. Barriers to prenatal detection of congenital heart disease: a population-based study. Ultrasound Obstet Gynecol. 2012 Oct;40(4):41825.

40 Hildebrand E, Dahlgren MA, Sved C, Gottvall T, Blomberg M, Janerot-Sjoberg B. Impact of a standardized training program on midwives' ability to assess fetal heart anatomy by ultrasound. BMC Med Imaging. 2014 Jun;14: 20.

41 Hunter S, Heads A, Wyllie J, Robson S. Prenatal diagnosis of congenital heart disease in the northern region of England: benefits of a training programme for obstetric ultrasonographers. Heart. 2000 Sep;84(3):294-8.

42 Radiology AC of, editor. American College of Radiology Practice Guideline for the Performance of Obstetrical Ultrasound [Internet]. Reston, VA; 2007. Available from: http:// www.acr.org/SecondaryMainMenuCategories/quality_safety/guidelines/us/us_obstetrical.aspx.

43 Levi S. Ultrasound in prenatal diagnosis: polemics around routine ultrasound screening for second trimester fetal malformations. Prenat Diagn. 2002 Apr;22(4):285-95.

44 Acherman RJ, Evans WN, Luna CF, Rollins R, Kip KT, Collazos JC, et al. Prenatal detection of congenital heart disease in southern $\mathrm{Ne}$ vada: the need for universal fetal cardiac evaluation. J Ultrasound Med. 2007 Dec;26(12): 1715-9.

45 AIUM Practice Guideline for the Performance of Obstetric Ultrasound Examinations. AIUM Practice Guideline for the Performance of Obstetric Ultrasound Examinations. J Ultrasound Med. 2013;32(6): 1083-101.

46 Ravi P, Mills L, Fruitman D, Savard W, Colen T, Khoo N, et al. Population Trends in Prenatal Detection of Transposition of Great Arteries: Impact of Obstetrica Screening Ultrasound Guidelines. Ultrasound Obstet Gynecol. 2018 May;51(5):659-664.

47 Carvalho J, Allan L, Chaoui R, Copel J, DeVore G, Hecher K, et al. ISUOG Practice Guidelines (updated): sonographic screening examination of the fetal heart. Ultrasound Obstet Gynecol. 2013 Mar;41(3):34859.

48 Sairam S, Awadh AM, Cook K, Papageorghiou AT, Carvalho JS. Impact of audit of routine second-trimester cardiac images using a novel image-scoring method. Ultrasound Obstet Gynecol. 2009 May;33(5):54551.

49 Ursem NT, Peters IA, Kraan-van der Est MN Reijerink-Verheij JC, Knapen MF, CohenOverbeek TE. An Audit of Second-Trimester Fetal Anomaly Scans Based on a Novel ImageScoring Method in the Southwest Region of the Netherlands. J Ultrasound Med. 2017 Jun; 36(6):1171-9. 
50 Jaudi S, Du Montcel ST, Fries N, Nizard J, Desfontaines VH, Dommergues M. Online evaluation of fetal second-trimester fourchamber view images: a comparison of six evaluation methods. Ultrasound Obstet Gynecol. 2011 Aug;38(2):185-90.

51 Jaudi S, Granger B, Herpin CN, Fries N, Du Montcel ST, Dommergues M. Online audit and feedback improve fetal second-trimester four-chamber view images: a randomised controlled trial. Prenat Diagn. 2013 Oct; 33(10):959-64.

52 Sklansky MS, Berman DP, Pruetz JD, Chang RK. Prenatal screening for major congenital heart disease: superiority of outflow tracts over the 4-chamber view. J Ultrasound Med. 2009 Jul;28(7):889-99.

53 Bromley B, Estroff JA, Sanders SP, Parad R, Roberts D, Frigoletto FD Jr, et al. Fetal echocardiography: accuracy and limitations in a population at high and low risk for heart defects. Am J Obstet Gynecol. 1992 May;166(5): 1473-81.

54 Cuneo BF, Curran LF, Davis N, Elrad H. Trends in Prenatal Diagnosis of Critical Cardiac Defects in an Integrated Obstetric and Pediatric Cardiac Imaging Center. J Perinatol. 2004 Nov;24(11):674-8.

55 Letourneau KM, Horne D, Soni RN, McDonald KR, Karlicki FC, Fransoo RR. Advancing
Prenatal Detection of Congenital Heart Disease: A Novel Screening Protocol Improves Early Diagnosis of Complex Congenital Heart Disease. J Ultrasound Med. 2018 May;37(5): 1073-9.

56 Nicholls D, Sweet L, Hyett J. Psychomotor skills in medical ultrasound imaging: an analysis of the core skill set. J Ultrasound Med. 2014 Aug;33(8):1349-52.

57 Valeri L, VanderWeele TJ. Mediation analysis allowing for exposure-mediator interactions and causal interpretation: Theoretical assumptions and implementation with SAS and SPSS macros. Psychol Methods. 2013 Jun; 18(2):137-50. 